\title{
Sub-monolayer film growth of a volatile lanthanide complex on metallic surfaces
}

\author{
Hironari Isshiki ${ }^{* 1}$, Jinjie Chen ${ }^{1}$, Kevin Edelmann ${ }^{1,2}$ and Wulf Wulfhekel ${ }^{1,2}$
}

\author{
Full Research Paper \\ Address: \\ ${ }^{1}$ Physikalisches Institut, Karlsruhe Institute of Technology (KIT), \\ Wolfgang-Gaede-Straße 1, 76131 Karlsruhe, Germany, and ${ }^{2}$ Institut \\ for Nanotechnology, Karlsruhe Institute of Technology (KIT), \\ Hermann-von-Helmholtz-Platz 1, 76344 Karlsruhe, Germany \\ Email: \\ Hironari Isshiki* - hironari.isshiki@kit.edu \\ * Corresponding author \\ Keywords: \\ $\beta$-diketonate; molecular films; scanning tunneling microscopy; \\ terbium; volatile lanthanide complex
}

Beilstein J. Nanotechnol. 2015, 6, 2412-2416. doi:10.3762/bjnano.6.248

Received: 14 September 2015

Accepted: 04 December 2015

Published: 16 December 2015

This article is part of the Thematic Series "Functional nanostructures optical and magnetic properties".

Guest Editor: P. Leiderer

() 2015 Isshiki et al; licensee Beilstein-Institut. License and terms: see end of document.

\begin{abstract}
We deposited a volatile lanthanide complex, tris(2,2,6,6-tetramethyl-3,5-heptanedionato)terbium(III), onto metal surfaces of $\mathrm{Cu}(111), \mathrm{Ag}(111)$ and $\mathrm{Au}(111)$ in vacuum and observed well-ordered sub-monolayer films with low temperature (5 K) scanning tunneling microscopy. The films show a distorted three-fold symmetry with a commensurate structure. Scanning tunneling spectroscopy reveals molecular orbitals delocalized on the ligands of the molecule. Our results imply that this complex can be transferred onto the metal substrates without molecular decomposition or contamination of the surface. This new rare-earth-based class of molecules broadens the choice of molecular magnets to study with scanning tunneling microscopy.
\end{abstract}

\section{Introduction}

Several carefully designed metal-organic molecules with magnetic-ion cores exhibit long spin-relaxation times for the reversal of the localized magnetic moment at low temperatures. These molecules are called single-molecule magnets (SMMs), because the magnetic properties are attributed to the individual single molecules as a result of the quantum mechanical interaction of the local magnetic moment and the ligand field [1]. Lanthanide-based SMMs have attracted much interest due to the potentially huge energy barrier for the reversal of magnetization [2]. This is an advantage from an applications viewpoint for magnetic storage devices based on single molecules. The investigation of individual molecules is crucial to understand the physics of SMMs. Scanning tunneling microscopy (STM) is one of few methods that can reveal the magnetic properties on the level of single molecules. The magnetic properties of single ions and single molecules of transition metals have been widely investigated with STM [3-6]. However, there are few studies on lanthanide-based SMMs with low-temperature STM [7,8] despite the variety of reports of their peculiar magnetic properties. One plausible reason is the difficulty in transferring them onto substrates in an ordered and clean way. Because of the huge molecular mass of lanthanide-based SMMs, many of them 
cannot be sublimed without decomposition, even in vacuum. Some studies have suggested methods other than vacuum deposition to solve the problem, but they are limited by the resulting level of contamination of the surface [9]. Finding a class of rare-earth SMMs that can be suitably transferred would be a significant step forward towards the application of magnetic molecular devices in which well-defined homogeneous molecular structures are required.

The $\beta$-dikenonate lanthanide(III) series have been known as volatile lanthanide complexes since the 1970s and have been used as precursors in chemical vapor deposition in the thin-film industry [10]. However, to the best of our knowledge, there has been only one paper that reports on the characterization of isolated molecules of ruthenium (platinum group metal) $\beta$-dikenonate with low-temperature STM [11]. Tris(2,2,6,6tetramethyl-3,5-heptanedionato)lanthanide(III) ( $\operatorname{Ln}(\text { thd })_{3}$ ) has the simplest molecular structure among them and is highly volatile thermally stability $[12,13]$. In this molecule, the lanthanide(III) ion is coordinated by three $\beta$-dikenonate ligands (see Figure 1) and the total charge of the molecule is zero. Recent DFT calculations for $\operatorname{Ln}(\text { thd })_{3}$ in gas phase show that the $\mathrm{D}_{3}$ symmetry structure corresponds to the minimum of the potential energy [14]. Though remarkable magnetic properties of $\operatorname{Ln}(\mathrm{thd})_{3}$ in bulk have not been reported, some of their derivatives exhibit SMM behavior [15]. It thus might be interesting to investigate $\operatorname{Ln}(\text { thd })_{3}$ with low-temperature STM. In this work, we chose $\mathrm{Tb}(\mathrm{thd})_{3}(\mathrm{~Tb}=$ terbium $)$ and deposited molecules on $\mathrm{Au}(111), \mathrm{Ag}(111)$ and $\mathrm{Cu}(111)$ surfaces to explore the transferability of lanthanide molecules onto metal surfaces without decomposition.

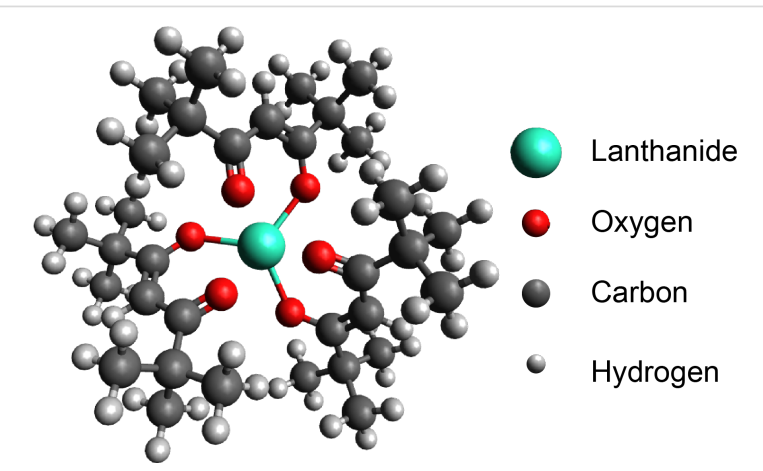

Figure 1: A ball-stick model of tris(2,2,6,6-tetramethyl-3,5-heptanedionato) lanthanide(III).

\section{Results and Discussion}

Figure $2 \mathrm{a}-\mathrm{f}$ shows STM topographies of $\mathrm{Tb}(\text { thd })_{3}$ deposited on $\mathrm{Cu}(111), \operatorname{Ag}(111)$ and $\mathrm{Au}(111)$, respectively. The imaging parameters are given in the caption. The white arrows indicate the [1 $\overline{1} 0]$ direction, which was determined from images with atomic resolution of each surface. We observed large molecular islands of $\mathrm{Tb}(\mathrm{thd})_{3}$ growing homogeneously on $\mathrm{Cu}(111)$ and $\mathrm{Ag}(111)$ and very few isolated molecules on these substrates (see Figure 2a,c). Thus, the deposited molecules diffuse at room temperature on the substrate, and eventually, nucleation of islands occurs due to an attractive molecule-molecule interaction, resulting in sub-monolayer film growth. The island height relative to the substrate in the topography is $\approx 340 \mathrm{pm}$ at $1 \mathrm{~V}$ sample bias, but depends on the sample bias in a sensitive manner. Additionally, on $\mathrm{Au}(111)$, we observed isolated molecules and small clusters at the elbow sites of the $\mathrm{Au}(111)$ herringbone reconstruction [16], but no large islands at this coverage (see Figure 2e). Figure $2 \mathrm{f}$ shows an isolated molecule in the center, and two clusters containing three molecules (i.e., molecular trimers). The cluster formation at the elbow sites of the herringbone indicates higher adsorption energy at these sites. The molecules can attach here but cannot diffuse further on the surface to form larger islands at room temperature. This
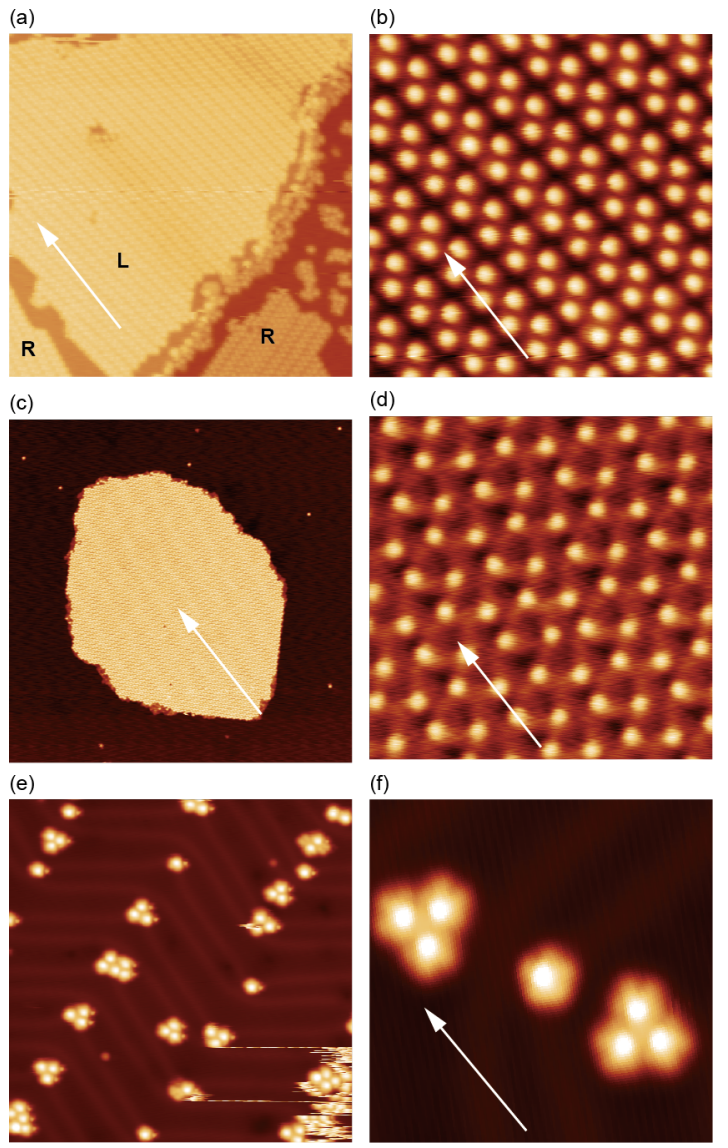

Figure 2: STM topographies of $\mathrm{Tb}(\text { thd })_{3}(\mathrm{a}, \mathrm{b})$ on $\mathrm{Cu}(111)$, (c,d) on $\mathrm{Ag}(111)$, and (e,f) on $\mathrm{Au}(111)$. The image sizes are (a) $50 \times 50 \mathrm{~nm}^{2}$, (c) $180 \times 180 \mathrm{~nm}^{2}$, (e) $40 \times 40 \mathrm{~nm}^{2}$ and (b,d,f) $10 \times 10 \mathrm{~nm}^{2}$. The white arrows indicate the $[1 \overline{1} 0]$ direction of the (111) surfaces. The labels $R$ and $L$ in (a) show the chirality of the film. Set point: $(a, b)-0.8 \mathrm{~V}, 70 \mathrm{pA}$, (c) $-0.8 \mathrm{~V}, 100 \mathrm{pA},(\mathrm{d})-1 \mathrm{~V}, 50 \mathrm{pA}$, (e,f) $1 \mathrm{~V}, 50 \mathrm{pA}$. 
preferential nucleation at the elbow sites has been reported for other molecules $[17,18]$.

In the extended islands on $\mathrm{Cu}(111)$ and $\mathrm{Ag}(111)$, a quasi-triangular lattice composed of molecules is observed (see Figure $2 \mathrm{~b}, \mathrm{~d})$. On $\mathrm{Cu}(111)$, we observed a particular row-like structure: two-molecule-wide rows are formed separated by dark stripes along a direction which is $+11^{\circ}$ rotated from [1 $\left.1 \overline{0} 0\right]$ (see Figure 2b). Looking at Figure 2a closely, we find two kinds of films, labeled by $\mathrm{R}$ and $\mathrm{L}$, which are $-11^{\circ}$ and $+11^{\circ}$ rotated from the $[1 \overline{1} 0]$ direction, respectively. The domains are related by a mirror operation along $[1 \overline{1} 0]$. Thus, taking into account the symmetry of the substrate, the two domains represent opposite chirality regarding the full structure of substrate and film. To investigate the superstructure of the molecular films, we superimposed a schematic model of $\mathrm{Cu}(111)$ and $\mathrm{Ag}(111)$ lattices on STM topographies of the films with enhanced contrast, as shown in Figure 3a,b. The analysis reveals that the molecular films assemble in a commensurate manner. Note that the adsorption site of the molecules with respect to the lateral position (on top, three-fold hollow site, etc.) could not be determined in our model since we were unable to obtain atomically resolved images of the substrates and molecules at the same time. The unit cells can nevertheless be represented by using vector $\mathbf{s}$ and $\mathbf{t}$ ( $\mathbf{s}^{\prime}$ and $\mathbf{t}^{\prime}$ ) for the lattice vector of $\mathrm{Cu}(111)$ $(\operatorname{Ag}(111))$ as follows:

$$
\left(\begin{array}{l}
A \\
B
\end{array}\right)=\left(\begin{array}{cc}
4 & 1 \\
-5 & 7
\end{array}\right)\left(\begin{array}{l}
\mathbf{s} \\
\mathbf{t}
\end{array}\right)
$$

for films on $\mathrm{Cu}(111)$ and,

$$
\left(\begin{array}{l}
A^{\prime} \\
B^{\prime}
\end{array}\right)=\left(\begin{array}{cc}
9 & 0 \\
-5 & 10
\end{array}\right)\left(\begin{array}{l}
\mathbf{s}^{\prime} \\
\mathbf{t}^{\prime}
\end{array}\right)
$$

for films on $\operatorname{Ag}(111)$. The complicated structure of the molecular films is the result of the competition between intermolecular interactions and molecule-substrate interactions. The creation of these commensurate lattices implies that the molecules are transferred onto substrates without decomposition and a relatively strong molecule-substrate interaction is maintained.

We took $d I / d V$ spectra on a molecule in a trimer on $\mathrm{Au}(111)$ to determine the local density of state (DOS) of the adsorbed molecules. The spectra of a molecule (black line) and the $\mathrm{Au}$ substrate (blue line) are shown in Figure 4a. The most prominent features in the spectra are marked by arrows at $+350 \mathrm{mV}$ and $+650 \mathrm{mV}$. The peak at about $-400 \mathrm{mV}$ on $\mathrm{Au}(111)$ is caused by the surface state of gold [19]. To see the particular

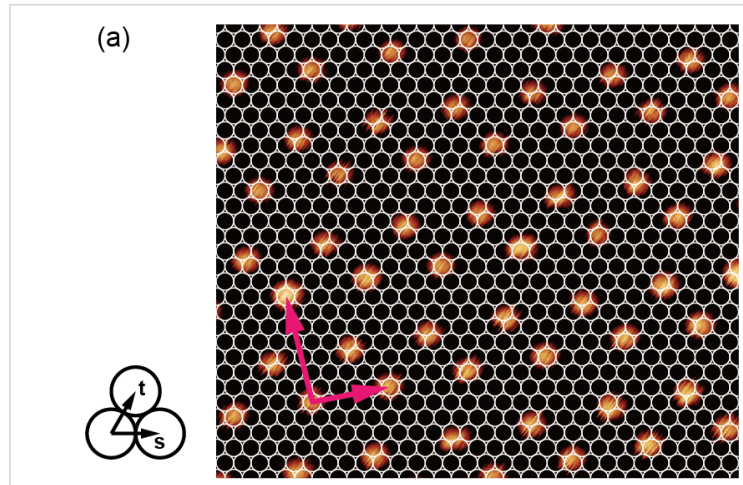

(b)

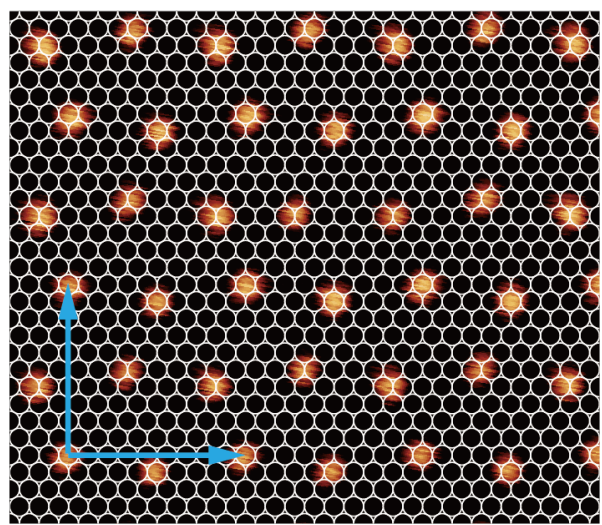

Figure 3: STM topographies of $\mathrm{Tb}(\text { thd })_{3}$ films (a) on $\mathrm{Cu}(111)$ and (b) on $\mathrm{Ag}(111)$ with the model of the substrate lattices. The white circles represent $\mathrm{Cu}$ or $\mathrm{Ag}$ atoms. The nearest neighbor distance of $\mathrm{Cu}$ $(\mathrm{Ag})$ atoms of substrate is $255 \mathrm{pm}(288 \mathrm{pm})$ in this model. The vector $\mathrm{t}$ and $\mathbf{s}$ shown in left lower of (a) are lattice vector of the substrate. The unit vector of films are shown as red and blue allows in each panel.

distribution of the DOS of the molecules, we performed $d I / d V$ mapping on the trimer. The $d I / d V$ maps at bias voltages of $-550 \mathrm{mV},+100 \mathrm{mV},+350 \mathrm{mV}$ and $+650 \mathrm{mV}$, together with their corresponding topographies, are shown in Figure $4 \mathrm{~b}$. The corrugation of the DOS on the substrate represents the standing waves caused by impurity scattering of the electrons of the surface state [20]. At $+350 \mathrm{mV}$ and $+650 \mathrm{mV}$, where the maxima in the $d I / d V$ spectrum were found, the DOS is localized on the molecules, that is, the shape represents the molecular orbitals. These significantly differ from the topography (e.g., the center of the molecules is bright in the topography, but it is dark in the $d I / d V$ map). At the voltages other than $+350 \mathrm{mV}$ and $+650 \mathrm{mV}$, the shapes of the local DOS are more similar to the topographic images. This implies that the topographic images more likely represent the geometrical height of the molecules.

\section{Conclusion}

We showed that $\mathrm{Tb}(\text { thd })_{3}$ complexes can be transferred onto metallic substrates by sublimation without decomposition or surface contamination. Furthermore, we showed that well- 

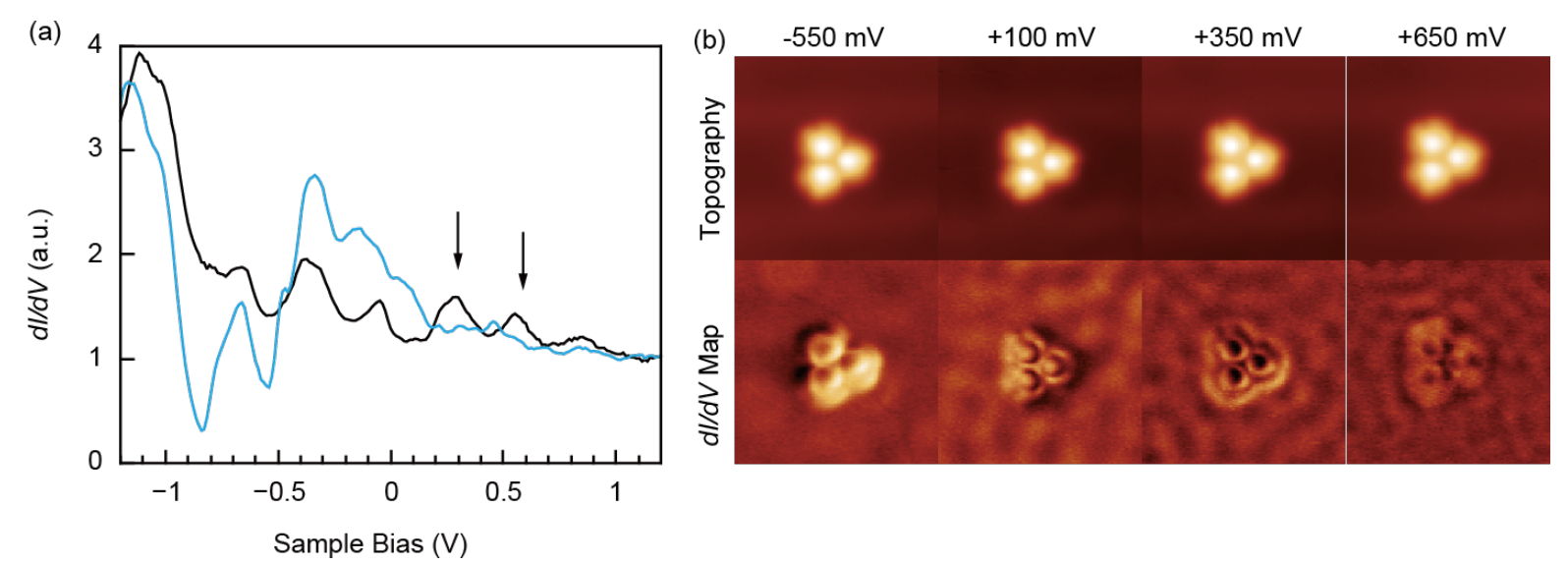

Figure 4: (a) $d I / d V$ spectra of a molecule in a trimer (black line) and on the Au substrate (blue line). (b) STM topography and $d I / d V$ maps at the indicated voltages.

ordered monolayer films of lanthanide molecules are formed on $\mathrm{Cu}(111)$ and $\mathrm{Ag}(111)$. Due to the chemical similarity of all rareearth elements, we speculate that similar complexes with different lanthanide cores can be sublimed as well. Thus, with this work, we have broadened the molecular species available for the study of rare-earth molecular magnetism.

\section{Experimental}

All experiments other than the molecule deposition and Ar sputtering were done in ultra-high vacuum conditions $\left(\approx 10^{-10}\right.$ mbar $)$. The $\mathrm{Tb}(\mathrm{thd})_{3}$ compound of $99 \%$ purity was purchased from Alfa Aesar and degassing was carefully performed by heating to $\approx 325 \mathrm{~K}$ in a ceramic crucible for hours prior to evaporation. The $\mathrm{Cu}(111), \mathrm{Ag}(111)$ and $\mathrm{Au}(111)$ single crystal substrates were cleaned with a standard Ar sputtering and annealing processes in a separate preparation chamber. After annealing and cooling down to room temperature, the substrates were transferred to a molecule deposition chamber and were exposed to a molecule flow of $\approx 0.1$ monolayers $/ \mathrm{s}$ for several seconds at a sublimation temperature of $\approx 335 \mathrm{~K}$. The pressure during deposition was $\approx 8 \times 10^{-8}$ mbar. After deposition, the samples were immediately transferred to the STM chamber and cooled down to $5 \mathrm{~K}$. The measurements were done with a homebuilt STM [21]. During the measurement, the sample temperature was kept at $\approx 5 \mathrm{~K}$. The $d I / d V$ spectra were taken using a standard lock-in amplifier technique with a $487 \mathrm{~Hz}$ modulation frequency and $20 \mathrm{mV}$ modulation voltage with an open feedback loop. The $d I / d V$ maps were recorded with the same lock-in parameters but with a closed feedback loop.

\section{Acknowledgements}

We acknowledge funding by the Alexander-von-Humboldt Foundation and the Landesstiftung Baden-Württemberg.

\section{References}

1. Gatteschi, D.; Sessoli, R. Angew. Chem., Int. Ed. 2003, 42, 268-297. doi:10.1002/anie.200390099

2. Ishikawa, N.; Sugita, M.; Ishikawa, T.; Koshihara, S.; Kaizu, Y. J. Am. Chem. Soc. 2003, 125, 8694-8695. doi:10.1021/ja029629n

3. Heinrich, A. J.; Gupta, J. A.; Lutz, C. P.; Eigler, D. M. Science 2004, 306, 466-469. doi:10.1126/science.1101077

4. Hirjibehedin, C. F.; Lin, C.-Y.; Otte, A. F.; Ternes, M.; Lutz, C. P.; Jones, B. A.; Heinrich, A. J. Science 2007, 317, 1199-1203. doi:10.1126/science.1146110

5. Tsukahara, N.; Noto, K.-i.; Ohara, M.; Shiraki, S.; Takagi, N.; Takata, Y.; Miyawaki, J.; Taguchi, M.; Chainani, A.; Shin, S.; Kawai, M. Phys. Rev. Lett. 2009, 102, 167203. doi:10.1103/PhysRevLett.102.167203

6. Meier, F.; Zhou, L.; Wiebe, J.; Wiesendanger, R. Science 2008, 320, 82-86. doi:10.1126/science.1154415

7. Fahrendorf, S.; Atodiresei, N.; Besson, C.; Caciuc, V.; Matthes, F.; Blügel, S.; Kögerler, P.; Burgler, D. E.; Schneider, C. M. Nat. Commun. 2013, 4, 2425. doi:10.1038/ncomms3425

8. Komeda, T.; Isshiki, H.; Liu, J.; Zhang, Y.-F.; Lorente, N.; Katoh, K.; Breedlove, B. K.; Yamashita, M. Nat. Commun. 2011, 2, 217. doi:10.1038/ncomms1210

9. Vitali, L.; Fabris, S.; Conte, A. M.; Brink, S.; Ruben, M.; Baroni, S.; Kern, K. Nano Lett. 2008, 8, 3364-3368. doi:10.1021/nl801869b

10. Hampden-Smith, M. J.; Kodas, T. T. Chem. Vap. Deposition 1995, 1, 8-23. doi:10.1002/cvde.19950010103

11. Munery, S.; Ratel-Ramond, N.; Benjalal, Y.; Vernisse, L.; Guillermet, O.; Bouju, X.; Coratger, R.; Bonvoisin, J. Eur. J. Inorg. Chem. 2011, 2698-2705. doi:10.1002/ejic.201100116 12. Sicre, J. E.; Dubois, J. T.; Eisentraut, K. J.; Sievers, R. E. J. Am. Chem. Soc. 1969, 91, 3476-3481. doi:10.1021/ja01041a011

13. Sievers, R. E.; Sadlowski, J. E. Science 1978, 201, 217-223. doi:10.1126/science.201.4352.217

14. Sliznev, V. V.; Belova, N. V.; Girichev, G. V. Comput. Theor. Chem. 2015, 1055, 78-87. doi:10.1016/j.comptc.2014.12.013

15. Chilton, N. F.; Langley, S. K.; Moubaraki, B.; Soncini, A.; Batten, S. R.; Murray, K. S. Chem. Sci. 2013, 4, 1719-1730. doi:10.1039/c3sc22300k 16. Narasimhan, S.; Vanderbilt, D. Phys. Rev. Lett. 1992, 69, 1564-1568. doi:10.1103/PhysRevLett.69.1564 
17. Yokoyama, T.; Yokoyama, S.; Kamikado, T.; Okuno, Y.; Mashiko, S. Nature 2001, 413, 619-621. doi:10.1038/35098059

18. Böhringer, M.; Morgenstern, K.; Schneider, W.-D.; Berndt, R.; Mauri, F.; De Vita, A.; Car, R. Phys. Rev. Lett. 1999, 83, 324-327. doi:10.1103/PhysRevLett.83.324

19. Davis, L. C.; Everson, M. P.; Jaklevic, R. C.; Shen, W. Phys. Rev. B 1991, 43, 3821-3830. doi:10.1103/PhysRevB.43.3821

20. Crommie, M. F.; Lutz, C. P.; Eigler, D. M. Nature 1993, 363, 524-527. doi:10.1038/363524a0

21. Zhang, L.; Miyamachi, T.; Tomanić, T.; Dehm, R.; Wulfhekel, W. Rev. Sci. Instrum. 2011, 82, 103702. doi:10.1063/1.3646468

\section{License and Terms}

This is an Open Access article under the terms of the Creative Commons Attribution License

(http://creativecommons.org/licenses/by/2.0), which permits unrestricted use, distribution, and reproduction in any medium, provided the original work is properly cited.

The license is subject to the Beilstein Journal of

Nanotechnology terms and conditions:

(http://www.beilstein-journals.org/bjnano)

The definitive version of this article is the electronic one which can be found at: doi:10.3762/bjnano.6.248 